\title{
Layer-Specific Touch-Dependent Facilitation and Depression in the Somatosensory Cortex during Active Whisking
}

\author{
Dori Derdikman, Chunxiu Yu, Sebastian Haidarliu, Knarik Bagdasarian, Amos Arieli, and Ehud Ahissar \\ Department of Neurobiology, The Weizmann Institute of Science, Rehovot 76100, Israel
}

Brains adapt to new situations by retuning their neurons. The most common form of neuronal adaptation, typically observed with repetitive stimulations of passive sensory organs, is depression (responses gradually decrease until stabilized). We studied cortical adaptation when stimuli are acquired by active movements of the sensory organ. In anesthetized rats, artificial whisking was induced at $5 \mathrm{~Hz}$, and activity of individual neurons in layers 2-5 was recorded during whisking in air (Whisking condition) and whisking against an object (Touch condition). Response strengths were assessed by spike counts. Input-layer responses (layers 4 and $5 \mathrm{a}$ ) usually facilitated during the whisking train, whereas superficial responses (layer 2/3) usually depressed. In layers $2 / 3$ and 4 , but not $5 \mathrm{a}$, responses were usually stronger during touch trials than during whisking in air. Facilitations were specific to the protraction phase; during retraction, responses depressed in all layers and conditions. These dynamic processes were accompanied by a slow positive wave of activity progressing from superficial to deeper layers and lasting for $\sim 1 \mathrm{~s}$, during the transient phase of response. Our results indicate that, in the cortex, adaptation does not depend only on the level of activity or the frequency of its repetition but rather on the nature of the sensory information that is conveyed by that activity and on the processing layer. The input and laminar specificities observed here are consistent with the hypothesis that the paralemniscal layer $5 \mathrm{a}$ is involved in the processing of whisker motion, whereas the lemniscal barrels in layer 4 are involved in the processing of object identity.

Key words: active touch; adaptation; lemniscal; paralemniscal; barrels; whisker

\section{Introduction}

The vibrissal somatosensory system of rodents is an active sensing system (Ahissar and Arieli, 2001; Kleinfeld et al., 2006); during tactile exploration, rats use rapid whisker movements while sampling the physical environment around them (Vincent, 1912; Welker, 1964; Gustafson and Felbain-Keramidas, 1977; Carvell and Simons, 1990; Brecht et al., 1997). To obtain sensory information, rat whiskers move forth and back with a rhythmic motion (whisking) at 4-25 Hz (Welker, 1964; Carvell and Simons, 1990; Fanselow and Nicolelis, 1999; Kleinfeld et al., 1999; Berg and Kleinfeld, 2003; Knutsen et al., 2006). Experimentally, deflections of passive whiskers can be useful for studying responses that occur during behavioral epochs in which the whiskers are not actively moved, such as when running along walls without whisking. However, such passive stimuli are less relevant for cases in which rats whisk actively. While whisking, rats apply force on

Received March 1, 2006; revised Aug. 3, 2006; accepted Aug. 3, 2006.

This work was supported by the Israel Science Foundation, the Minerva Foundation with funding from the Federal German Ministry for Education and Research, the German Federal Ministry of Education and Research-Israeli Ministry of Science and Technology Foundation, and the Human Frontier Science Program. D.D. was supported by a fellowship from the Center for Complexity Science (Jerusalem, Israel). K.B. was supported by the Giladi program, Ministry of Absorption (Israel). E.A. holds the Helen Diller Family Professorial Chair of Neurobiology. We thank Jaime Heiss, Per Magne Knutsen, Ilan Lampl, Marcin Szwed, Barbara Schick, and the two anonymous reviewers for useful comments on this manuscript and Daniel Goldian and Naama Rubin for technical assistance.

Correspondence should be addressed to Ehud Ahissar, Department of Neurobiology, The Weizmann Institute of Science, Rehovot 76100, Israel. E-mail: Ehud.Ahissar@weizmann.ac.il.

D. Derdikman's present address: Centre for the Biology of Memory, Medical-Technical Research Centre, Norwegian University of Science and Technology, 7489 Trondheim, Norway.

DOI:10.1523/JNEUROSCI.0918-06.2006

Copyright $\odot 2006$ Society for Neuroscience $\quad$ 0270-6474/06/269538-10\$15.00/0 objects in their paths. The force of the muscle acts on the base of the whisker, whereas the force of the object acts on a point along the external shaft of the whisker. These two forces cause whiskers to bend considerably while contacting objects (Derdikman et al., 2003; Szwed et al., 2003; Knutsen et al., 2006). In contrast, during passive stimulation, force is applied only at a single point, and whiskers hardly bend.

Recently, Szwed et al. (2003) used artificial whisking in anesthetized rats, a method adapted from Zucker and Welker (1969) and from Brown and Waite (1974), to investigate encoding of active touch by whiskers. While recording extracellularly from first-order neurons in the trigeminal ganglion, they found that whisker protraction-angle and object-touch are encoded by three main classes of first-order trigeminal neurons (Szwed et al., 2003). "Touch neurons" responded when the principal whisker of a neuron touched an object but did not respond when the rat whisked artificially with no object in the path of the whisker. "Whisking neurons" responded when the rat was whisking but gave no additional response when an object obstructed the path of the whisker. "Whisking/Touch neurons" responded to both whisking and touch (touch increased the mean response spike count by $\sim 200 \%$ on average). These active touch signals are conveyed in parallel up to the thalamus: whisking signals are conveyed by the paralemniscal, contact signals are conveyed by the extralemniscal [a pathway recently discovered by Pierret et al. (2000)], and complex whisking-touch signals are conveyed by the lemniscal pathway (Yu et al., 2006).

Here, responses of units in the barrel somatosensory cortex 
(Woolsey and Van der Loos, 1970) were examined using the same paradigm of artificial whisking in anesthetized rats as in the studies by Szwed et al. (2003) and Yu et al. (2006). We recorded extracellular spike activity of neurons in the rat barrel cortex and examined how these neurons responded during whisking and object contact. The most salient observation was that the dynamics exhibited by cortical neurons while adapting to the stimulus train were both layer specific and stimulus specific. Typically, when applying repetitive stimulations to passive sensory organs, cortical responses depress (Mountcastle et al., 1957; Hellweg et al., 1977; Simons, 1978; Ulanovsky et al., 2004). With our active stimulation paradigm, responses to stimuli presented at similar frequencies and producing similar initial responses either facilitated, did not change, or depressed, depending on the sensory information conveyed (i.e., presence or absence of an object) and on the cortical layer.

\section{Materials and Methods}

Animals and electrophysiology. Subjects were 42 male albino Wistar rats (250-350 g). Animal maintenance, manipulations, procedures, and surgeries were conducted in accordance with the National Institutes of Health Guide for the Care and Use of Laboratory Animals and were approved by the Institutional Animal Care and Use Committee of The Weizmann Institute. Surgical procedures were performed under general anesthesia with urethane (1.5 g/kg, i.p.), as described previously (Szwed et al., 2003). Supplemental doses of urethane (10\%) were administered as required. Atropine methyl nitrate $(0.3 \mathrm{mg} / \mathrm{kg}$, i.m. $)$ was administered to prevent respiratory complications. Body temperature was maintained at $37^{\circ} \mathrm{C}$. Anesthetized rats were secured in a stereotaxic device (SR-6; Narishige, Tokyo, Japan). An opening was made in the skull overlying the vibrissae barrel field of the primary somatosensory cortex of the right hemisphere ( $\sim 2-3 \mathrm{~mm}$ caudal and 5-6 $\mathrm{mm}$ lateral to bregma), and up to four tungsten microelectrodes (0.5-1.2 M ; Alpha Omega Engineering, Nazareth, Israel) were lowered until units that responded to manual mechanical whisker stimulations were encountered. Single units and multiunits were recorded, using procedures similar to those described by Ahissar et al. (2001). For each unit, its principal whisker (PW) was manually determined by repetitive stimulation of the whiskers in the contralateral whisker pad (Simons, 1978). Artifacts produced by electrical stimulation were isolated by an on-line spike-sorter (MSD-3.21; AlphaOmega Engineering) and removed on-line from the unit recordings.

Experimental paradigm. Artificial whisking was induced at $5 \mathrm{~Hz}$ in trains of 10 whisks each (100 ms protraction and $100 \mathrm{~ms}$ retraction), separated by intertrain intervals of $3 \mathrm{~s}$, in blocks of 12 or 24 trains (trials). Whisking movements were induced by stimulating the buccal motor branch of the facial nerve, as described by Szwed et al. (2003). Briefly, the nerve was surgically exposed and cut, and its distal end was mounted on bipolar silver electrodes. Bipolar, rectangular electrical pulses $(0.5-4.0 \mathrm{~V}$; $83 \mathrm{~Hz} ; 40 \mu$ s duration) were applied via an isolated pulse stimulator (model 2100; A-M Systems, Sequim, WA).

Whisker movements were recorded at 1000 frames/s with a fast digital video camera (MotionScope PCI 1000; Redlake, San Diego, CA). Video recordings were synchronized (within $1 \mathrm{~ms}$ ) with neurophysiological data. Blocks of whisking freely in the air were interleaved with blocks of artificial whisking against an object. Objects were positioned at $60-90 \%$ of the length of the PW of a neuron and $\sim 1-2 \mathrm{~mm}$ rostral to the rest position of the $\mathrm{PW}$. To imitate natural conditions as much as possible, to avoid changes of neuronal responsiveness resulting from whisker trimming (Kelly et al., 1999; Celikel et al., 2004), and to facilitate recording from more than a single unit during an experiment, all whiskers of the mystacial pad were left intact throughout an experiment. Thus, like in natural whisking, whiskers besides the PW contacted the object during whisker movement (see Fig. $1 B$ ). Yet, to enable systematic comparison of responses, precautions were taken so that the PW was always the first to touch the object during whisker protraction. Thus, when whiskers in the same arc were nearer to the object than the PW, the former were moved rostral to the object.
The object was positioned in front of the PW of unit(s) recorded from one of the recording electrodes (we recorded from up to four electrodes simultaneously, usually located in adjacent barrel columns, $0.3 \mathrm{~mm}$ apart). Only units for which that whisker was a PW (PW-group) or an adjacent whisker (AW; AW-group), were included in our analysis. Furthermore, units were excluded from analysis if they did not respond to stimulation, or if, according to video recordings, the PW (or AW for the AW-group) either did not touch the object during whisker protraction or did not detach from the object during whisker retraction.

Histological procedures. Procedures were identical to those used previously (Ahissar et al., 2001). Briefly, at the end of each recording session, electrolytic lesions were induced by passing electrical currents $(7.8 \mu \mathrm{A}$; $2 \times 4 \mathrm{~s}$; unipolar) through the tips of the recording electrodes. Brains were removed and cut either in coronal sections or in sections parallel to the barrel arcs and stained for cytochrome oxidase. Lesions located in the cortex could be seen clearly (see Fig. 3 ) and were classified as being in layer 2/3, layer 4 barrels, layer 4 septa, or layer $5 a$. In some cases $(n=9)$, neurons were recorded from two or three sites along the same penetration. In these cases, the more dorsal sites were localized along the penetration track according to the recording depth registered by the electrode positioning system (resolution of $1 \mu \mathrm{m}$; EPS, Alpha Omega Engineering). Classification of the cortical location of a lesion site was confirmed independently by two observers (S.H. and D.D.). Experiments in which recording sites could not be determined by histology were excluded from analysis if the recording depth was $>500 \mu \mathrm{m}$. When definitive histological evidence was lacking, but the recording depth was $<500 \mu \mathrm{m}(n=$ 14 ), units were classified as belonging to layers $2 / 3$. In our experience, units recorded at depths $<500 \mu \mathrm{m}$ below the dura were always histologically confirmed as belonging to supragranular layers. Layer 4 septal regions were identified after reconstruction of the barrel field from multiple slices. Because of the small width of typical septa $(\sim 100 \mu \mathrm{m})$, the probability of recording neurons located on the border of a neighboring barrel by an electrode located within the septa was not negligible. Thus, units recorded from electrode tips located in layer 4 septa were discarded from the study.

Data analysis. Trajectories of whisker movements were analyzed offline with a freely available application written in MatLab (Knutsen et al., 2005). Raster plots and peristimulus time-histograms (PSTHs) (1 ms bins, smoothed by convolution with a triangle of area 1 and a base of \pm 10 ms) were computed and examined for all trains of each cell. Average response latencies were computed from PSTHs as latency to half-peak [see Discussion in the study by Sosnik et al. (2001) for comparison of methods for estimating response latency]. Spike counts were calculated for the first $60 \mathrm{~ms}$ from the onset of protraction or retraction and per cycle. Sixty milliseconds were chosen to estimate the magnitude of the first response peak; typically, a postexcitatory suppression followed the first response peak during the first cycles (see PSTHs in Fig. 3). Amplitudes of response peaks were calculated as the maximum of the smoothed PSTH. Unless otherwise stated, error bars in the figures depict SEMs. Significance values were calculated using the nonparametric Wilcoxon rank sum, unless stated otherwise. Binomial distribution was used for estimating significance in Table 2. Normalization of spike count was achieved relative to the spike count in the first cycle, according to the following formula: normalized spike count $=\left[S_{\mathrm{i}}-S_{1}\right] /\left[S_{\mathrm{i}}+S_{1}\right]$ (Eq. 1), where $S_{\mathrm{i}}$ was the spike count during the protraction in the $i^{\text {th }}$ cycle, and $S_{1}$ was the protraction spike count in the first cycle. Thus, the normalized spike count attained positive values between 0 and 1 for facilitation and negative values from 0 to -1 for depression. In Figure 8, latency differences were emphasized by normalizing the PSTH of each unit to its maximal value for each condition before averaging.

Table 1. Location of single units used in this study

\begin{tabular}{llr}
\hline & Group & \\
\cline { 2 - 3 } Cortical location & PW & AW \\
\hline Layer 2/3 & 34 & 17 \\
Layer 4 barrels & 29 & 9 \\
Layer 5 a & 28 & 17 \\
Total & 91 & 43 \\
\hline
\end{tabular}




\section{Results \\ Artificial whisking and \\ experimental paradigm}

Artificial whisking in anesthetized rats was induced at $5 \mathrm{~Hz}$ by stimulating the facial motor nerve, similar to that in the study by Szwed et al. (2003). The blocks of whisking in free air (Whisking condition) were interleaved with blocks of whisking against an object (vertical pole) located $\sim 1-2 \mathrm{~mm}$ rostral to a selected whisker at $\sim 60-90 \%$ of the length of the whisker (Touch condition).

Single units $(n=238)$ in layers $2-5$ of urethane-anesthetized rats were recorded extracellularly. For each unit, the PW was determined as the whisker that caused the strongest response to manual mechanical stimulation (Simons, 1978). We classified a unit as belonging to the PW group if the object was positioned next to the PW of that unit and as belonging to the AW group if the object was positioned next to an AW of that unit. After excluding units not belonging to either group (see Materials and Methods), the final sample consisted of 130 single units in the PW group and different 61 single units in the AW group (Table 1). The single units in the PW group had a spontaneous rate of $1.99 \pm 0.22 \mathrm{spikes} / \mathrm{s}$ (mean $\pm \mathrm{SE} ; n=91$ ). In the AW group, the spontaneous rate was $1.66 \pm 0.30$ spikes/s $(n=43)$. The number of units in each layer is indicated in Table 1 . The units in the PW group that were located in layer $2 / 3$, layer 4 barrels, and layer $5 \mathrm{a}$ $(n=91)$ were subjected to extensive analysis. Units recorded in the AW group $(n=43)$ were subjected to comparative, less extensive analysis.

To determine the paths of the whiskers and the moments of touch, we recorded whisker trajectories using a high-speed video camera. Whisker trajectories were tracked with a fast digital video camera (1000 frames/s) synchronized with a neural data acquisition computer (Knutsen et al., 2005). We present here an example of such tracking: a recording of five electrical whisk-angle trajectories is shown in Figure $1 A$, both for the Whisking (black) and Touch (red) conditions. The noise in the unfiltered traces is partially attributable to actual movements of the whisker and to whisker-tracking errors. We tracked angle trajectories of the PW of 72 units ( $~ 55 \%$ of the units) in both Whisking and Touch conditions. In video recordings, the mean protraction angle was $12.2 \pm 6.7^{\circ}$ (mean $\pm \mathrm{SD}$ ) in the Touch condition and $14.5 \pm 6.6^{\circ}$ in the Whisking condition. The distal location of the object did not prevent the protraction of the base of the whisker; after contact with the object, the whisker continued to move while bending (Fig. $1 B$ ). Thus, the difference between the trajectories of the base of the whisker during the Touch and Whisking conditions was small (Fig. 1C,D). The difference in protraction amplitude between the Touch and Whisking conditions was only $\sim 2^{\circ}$ on average ( $\sim 15 \%$ of the average protraction amplitude). The object was usually positioned $\sim 1-2 \mathrm{~mm}$ in front of the resting position of the whisker, and the whisker touched the object on average $9.8 \pm 5.9 \mathrm{~ms}$ (mean $\pm \mathrm{SD}$ ) after protraction onset. This time of touch did not differ significantly during recording of units belonging to different layers (layer 2/3, $10.5 \pm 1.4 \mathrm{~ms}$; layer 4-barrel, $8.0 \pm 1.9 \mathrm{~ms}$; layer 5a, $9.2 \pm 3.0 \mathrm{~ms}$; mean $\pm \mathrm{SEM}$ ).

\section{Dynamics of unit activity during whisking and touch}

Individual cortical neurons displayed different response dynamics during Whisking and Touch trials. Examples of these differences are depicted in Figure 2, where responses of two single units to a train of 10 whisks at $5 \mathrm{~Hz}$ are depicted. The response of a layer 4 barrel single unit (Fig. $2 A, B, E$ ) was similar for Whisking and Touch conditions during the protraction phase of the first cycle $\left(P_{1}\right.$ in Fig. $2 A, B$ ) but differed considerably during later cycles (see aligned comparison of responses during the first cycle and during cycles $5-10$ in Fig. $2 E$ ). The protraction response in the Whisking condition was facilitated from the first $\left(P_{1}\right)$ to the second $\left(P_{2}\right)$ cycle and then continuously depressed, whereas the response in the Touch condition remained facilitated during later cycles. Furthermore, during the retraction phase, there was already a difference between responses in Touch and Whisking conditions in the first cycle $\left(R_{1}\right)$. This difference gradually disappeared in later cycles (compare $R_{1}$ and $R_{2}$ with $R_{\mathrm{i}}$ of later cycles). In contrast, a layer 5 a single unit did not demonstrate any marked differences between responses in the Whisking and Touch conditions (Fig. $2 C, D, E)$.

Similar response dynamics were evident in the mean population responses. When the responses of all recorded PW group units were summed [layer $2 / 3(n=34)$, layer 4 barrels $(n=29)$, and layer $5 \mathrm{a}(n=28)$ ] (Fig. 3$)$, the following trends became apparent: (1) the first-cycle response $\left(P_{1}\right.$ in Fig. $\left.3 A-C\right)$ was similar in magnitude in Touch and Whisking conditions; (2) following $P_{1}$, activity dropped below background level; (3) the response during whisker retraction in the first cycle $\left(R_{1}\right)$ was larger for Touch than for Whisking conditions in all three cortical layers; (4) for both Touch and Whisking conditions, activity increased in all three cortical layers during the $2-3$ cycles immediately after the first cycle; (5) during later cycles (cycles 5-10), the protraction response $\left(P_{\mathrm{i}}\right)$ of layer 4 barrel units was larger for the Touch than for the Whisking condition, while being of similar magnitude in layer $5 \mathrm{a}$ [this latter phase of the whisking train (cycles 5-10), in which responses in each condition remained more or less constant, is referred to herein as the steady state phase]; (6) in 

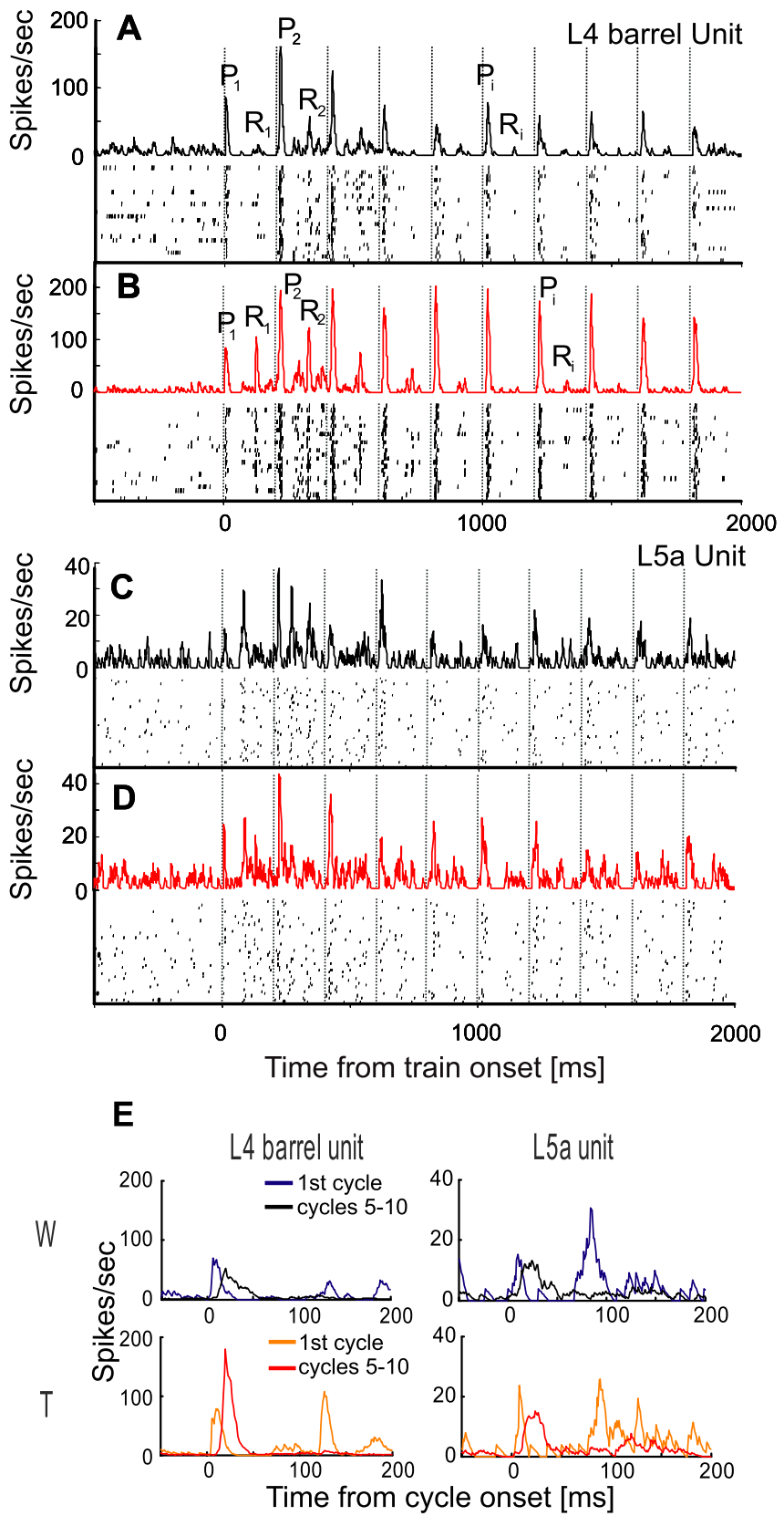

Figure 2. Dynamics of single-unit activity during whisking and touch. $A, B, A$ layer 4 barrel neuron during Whisking $(\boldsymbol{A})$ and Touch $(\boldsymbol{B})$ conditions. $\boldsymbol{C}, \boldsymbol{D}, \mathrm{A}$ layer 5 a cell during Whisking $(\boldsymbol{C})$ and Touch $(\boldsymbol{D})$ conditions. Protraction onset times are marked by dashed vertical lines every 200 ms. Both raster plots (bottom) and PSTHs (top) are shown. $P_{\mathrm{i}}$ denotes a specific response phase during the $i^{\text {th }}$ whisker protraction. $R_{\mathrm{i}}$ denotes a specific response phase during the $i^{\text {th }}$ whisker retraction. The whisker contacted the object $15 \mathrm{~ms}$ after each protraction onset in $\boldsymbol{B}$ and after 7 $\mathrm{ms}$ in $\boldsymbol{D}$. $\boldsymbol{E}$, Comparison of responses in first cycle (blue and orange lines) and in steady state (mean of cycles, 5-10; black and red lines) for the two neurons in $\boldsymbol{A}-\boldsymbol{D}$, in the Whisking condition (top panels) and Touch condition (bottom panels). spikes/sec, Spikes per second.

all three cortical layers, the response to retraction during steadystate cycles $\left(R_{\mathrm{i}}\right)$ was almost completely abolished in both Touch and Whisking conditions; and (7) the distribution of spike times along the whisking cycle changed from first cycle to steady state, most notably in layer 5a (Fig. 3D).

In general, Figure 3 demonstrates that layer $2 / 3$ responses at steady state were depressed compared with the first cycle, whereas those of the input layers were not. Furthermore, Figures 2 and 3 show that the two input layers differed in their dependency on touch; unlike layer 5a neurons, layer 4 barrel neurons exhibited different dynamics during Whisking and Touch trials, leading to different steady-state behaviors.

\section{Depression and facilitation during protraction phases}

To quantify the dynamics of response magnitude, we measured the spike count during the first $60 \mathrm{~ms}$ of each whisk cycle, a window during which whiskers were fully protracted (Fig. 1). Figure 4, $A-C$, depicts the development of spike counts from the first cycle to steady-state cycles in Whisking and Touch trials for the entire population recorded in each layer; spike counts were subtracted from the spike count during the first cycle and normalized (see Eq. 1 in Materials and Methods) and averaged across each population. In layer $2 / 3$ of the PW group, spike counts were significantly depressed from the first cycle to steady state for both Whisking ( $p=0.0014$; Wilcoxon) and Touch ( $p=0.032)$ conditions (Fig. $4 A, D$ ). In layer 4 barrels, the spike count was facilitated for the Touch $(p=0.0009)$ but not for the Whisking ( $p=$ 0.35 ) conditions (Fig. $4 B, E$ ). In layer $5 \mathrm{a}$, spike counts were facilitated for both Whisking and Touch conditions $(p=0.043$ for Whisking; $p=0.014$ for Touch) (Fig. $4 C, F$ ). Consistent with the average behavior, single unit analysis revealed that most of the units in layer $2 / 3$ were depressed from first cycle to steady state, layer 5 a units were mostly facilitated, and layer 4 barrels mostly facilitated in the Touch condition and had a mixed behavior in the Whisking condition (Fig. 4D-F, Table 2). Note that most of the response facilitation occurred already between the first and second whisks (Fig. 4B, C).

To assess the spatial extent of adaptation (both depression and facilitation), responses to AW contacts were analyzed in 43 neurons. Except for the Touch condition in layer 4 barrels, this group of cells exhibited adaptation profiles similar to those of the PW group neurons. Unlike responses to $\mathrm{PW}$ touch, responses to AW touch did not facilitate in layer 4 barrel neurons (Fig. $5 B, D)(p=$ $0.36 ; n=9)$. The response of layer $2 / 3$ cells of the AW group was slightly depressed (Fig. $5 A, D, E)(p=0.14$ for Touch condition; $p=0.09$ for Whisking condition; $n=16$ ), and that of layer $5 \mathrm{a}$ cells was facilitated (Fig. $5 C, D, E)(p=0.001$ for Touch condition; $p=0.002$ for Whisking condition; $n=17$ ) similar to the behavior of the PW group (Fig. $4 A, C$ ).

In summary, layer $2 / 3$ responses depressed while layer 5 a units facilitated during either whisking or touch with both PW and AW in all conditions (Fig. 5D,E). Layer 4 neurons displayed touch and whisker-specific facilitation: touch with the PW increased facilitation significantly, whereas touch with an AW decreased facilitation.

\section{Adaptation during retraction phases}

During each cycle, whiskers protracted for $\sim 100 \mathrm{~ms}$ and then retracted; retraction movement was completed within $<50 \mathrm{~ms}$ (Fig. 1). Neuronal responses during retraction typically depressed along the train in all layers. To quantify the dynamics of retraction response, spike counts were integrated from the $100-$ $160 \mathrm{~ms}$ time window in each cycle and normalized in relation to the retraction response in the first cycle (Eq. 1 in Materials and Methods). In all three cortical layers, during the first cycle, a clear response usually occurred during the retraction phase and diminished during steady state (Figs. 2, 3, compare $\mathrm{R}_{1}$ with $\mathrm{R}_{\mathrm{i}}$ ). Overall, there was also a significant difference in spike count during retraction between Touch and Whisking conditions in the first cycle ( $p=0.03$; Wilcoxon sign-rank test), a difference that diminished, along with the responses, at steady state. The dynamics of spike-count adaptation during retraction was somewhat 
different than that during protraction, although displayed a similar time course, leading to stabilization within approximately five cycles (Fig. 6). The difference in adaptation between whisking and touch displayed a complementary trend in protraction and retraction. Whereas neurons in layers $2 / 3$ and 4 adapted to higher spike counts during touch than during protraction in air (Fig. 4), they adapted to lower spike counts during detach than to retraction in air (Fig. 6).

\section{Steady-state responses}

The data above show that the dynamics of response magnitude during protraction differed between layers and between touch (Touch) and no-touch (Whisking) trials (Fig. 4). The difference between protraction response magnitudes in Touch and Whisking trials at steady state (cycles 5-10) was quantified by the touch index [TI $=$ $\left(S_{\mathrm{T}}-S_{\mathrm{W}}\right) /\left(S_{\mathrm{T}}-S_{\mathrm{W}}\right)$, where $S_{\mathrm{T}}$ is spike count during the first $60 \mathrm{~ms}$ of protraction in Touch trials, and $S_{\mathrm{W}}$ is the same during Whisking trials]. A TI of -1 indicates that the neuron responded at steady state only to the Whisking condition, whereas a TI of 1 indicates that the neuron responded at steady state only to the Touch condition. A touch index of 0 indicates that the neuron fired an equal amount of spikes in both conditions. The modes of the distributions of TI in layers $2 / 3$ and $5 a$ are at 0 , whereas the mode in layer 4 barrels was at $\mathrm{TI}=0.4$ (Fig. 7A-C). However, the differences between the medians were not significant (Fig. 7D) (Wilcoxon; $p=0.07$ for layer 4 barrel and layer $5 \mathrm{a} ; p>0.3$ for differences between layer $2 / 3$ and other layers).

\section{Dynamics of response latency}

In addition to spike-count dynamics, we also checked the development of response latencies (to half-peak response) from cycle to cycle. Usually, latencies increased from the first cycle to steady state, where most of the increment occurred during the first two to three cycles (Fig. $8 A, C, E$ ). Latency to half peak usually stabilized around shorter values in the Whisking than in the Touch conditions (Fig. 8, Table 3) $(p=0.006)$. This observed difference between Touch and Whisking conditions was also significant ( $p=0.01$ ) when latency was estimated as the median latency to first spike. The shorter latency in the Whisking than in the Touch condition was evident in the mean of individually normalized PSTHs during steady state. In all three cortical layers, the steadystate response rose earlier in the Whisking than in the Touch condition (Fig. $8 B, D, F$ ). Latencies of artificially induced active whisking (Table 3 ) were comparable with those found with passive stimuli in both rats and mice (Welker et al., 1993; Armstrong-James et al., 1992; Brumberg et al., 1999; Ahissar et al., 2001; Brecht and Sakmann, 2002; Manns et al., 2003).
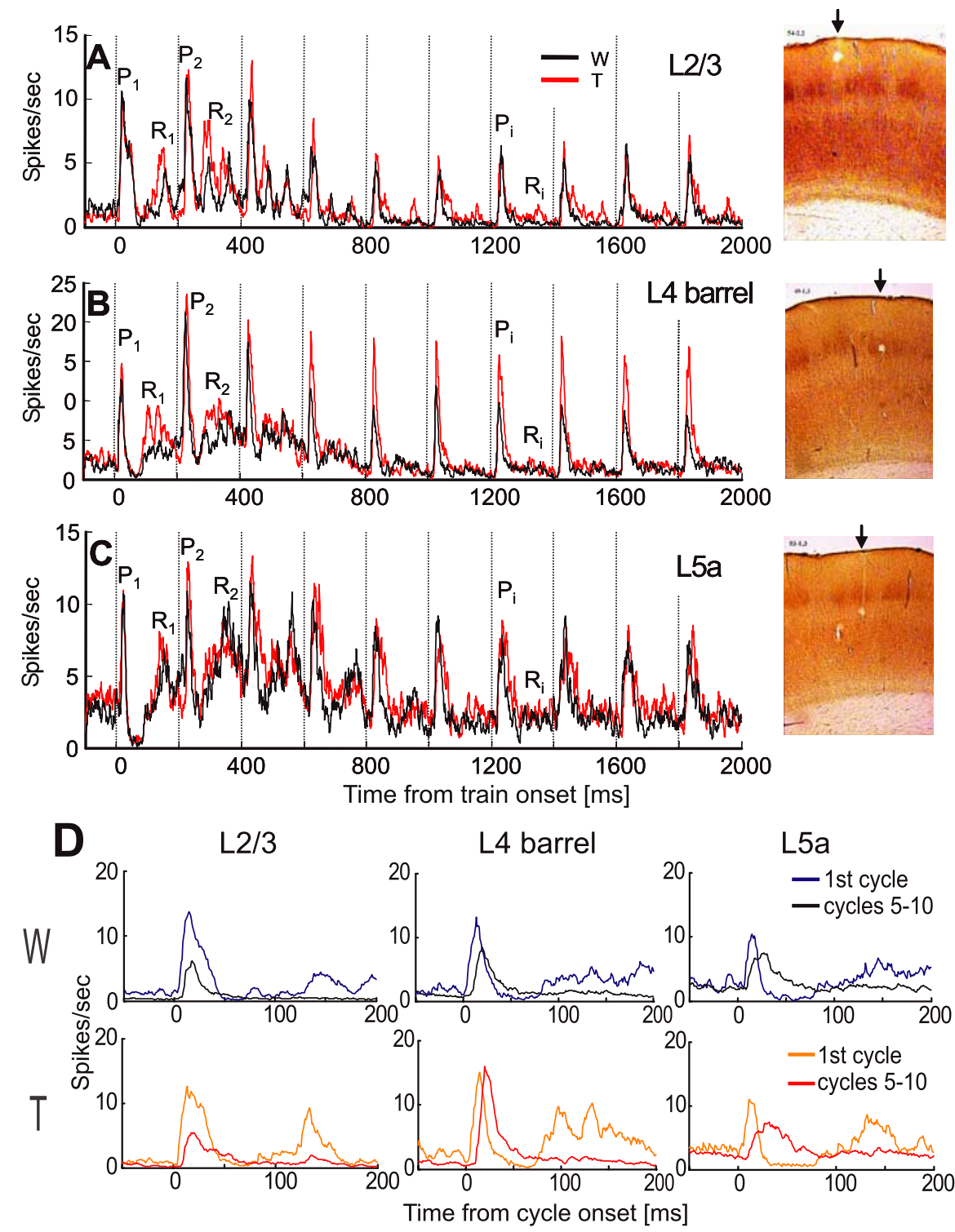

Figure 3. Population PSTHs for Touch (red) and Whisking (black) conditions in various cortical layers. $A$, Layer $2 / 3(L 2 / 3 ; n=$ 34 neurons). $\boldsymbol{B}$, Layer 4 barrels $(L 4 ; n=29)$. C, Layer $5 \mathrm{a}$ ( $(L 5 a ; n=28)$. Protraction onset times are marked by vertical dashed lines every $200 \mathrm{~ms} . P_{\mathrm{i}}$ and $R_{\mathrm{i}}$ denote specific response phases during protractions and retractions, respectively. Contact time was $10.5 \pm$ cortex with lesions in layers $2 / 3$ (top), 4 -barrel (middle), and 5 a (bottom) are presented at the right. The arrows point toward sites of lesions. $\boldsymbol{D}$, Comparison of mean responses in first cycle (blue and orange lines) and in steady state (black and red lines; mean of cycles, 5-10) for Whisking (top) and Touch (bottom) conditions. W, Whisking condition; T, Touch condition.

\section{Slow wave of response}

A slow response wave, expressed as an increase in activity during the first cycles (Fig. 3), was evident during the first $1000 \mathrm{~ms}$ of most responses. In the population response, the slow wave developed after the first excitation peak $\left(P_{1}\right)$ and lasted up to $\sim 800 \mathrm{~ms}$ from train onset (Fig. 3). Cessation of the slow wave allowed response dynamics to converge to a steady-state behavior after approximately five cycles. The cessation of the slow wave was usually accompanied by a reduction in spike count, mostly during the retraction phase (Figs. 2-4, 6). The slow wave component was characterized quantitatively by isolating it from the response using a low-pass filter (third-order Butterworth) with a cutoff frequency of $2 \mathrm{~Hz}$. The slow wave was clearly seen in all three cortical layers (Fig. 9A-C). The time to peak varied across layers: the two input layers (layers 4 barrels and 5a) exhibited longer 

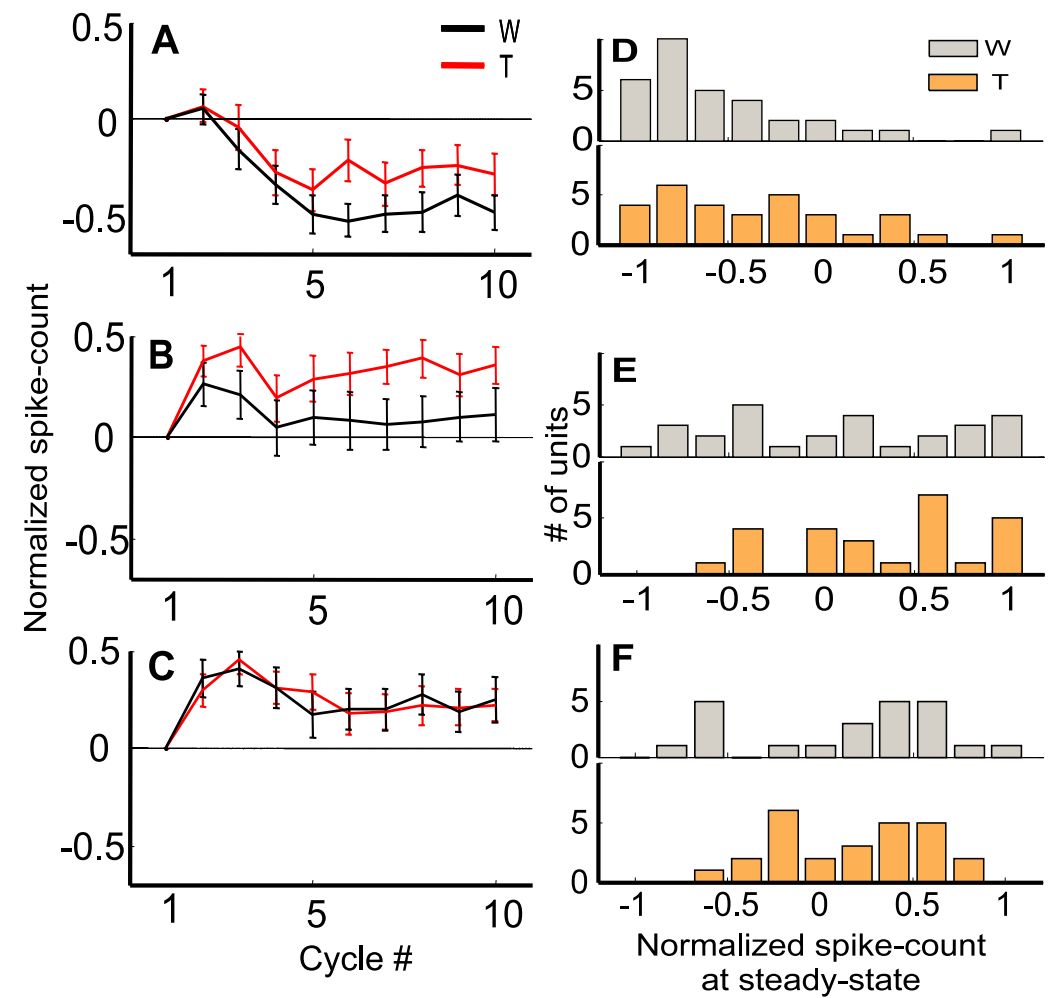

Figure 4. Dynamics of response magnitude of PW neurons during protraction. $\boldsymbol{A}-\boldsymbol{C}$, Mean normalized cycle spike count (mean \pm SEM; see Materials and Methods) as a function of cycle number for the PW group ( $\boldsymbol{A}$, layer $2 / 3$; $\boldsymbol{B}$, layer 4 barrels; $\boldsymbol{C}$, layer 5a) during artificial whisking in free air (black line) and against an object (red line). $\boldsymbol{D}-\boldsymbol{F}$, Distributions of normalized steady-state spike count of single units (gray, whisking only; orange, whisking against an object) in each of the layers ( $\boldsymbol{D}$, layer $2 / 3 ; \boldsymbol{E}$, layer 4 barrels; $\boldsymbol{F}$, layer 5a). W, Whisking condition; T, Touch condition.

Table 2. Distribution of facilitating and depressing units in the Touch condition and the Whisking condition

\begin{tabular}{|c|c|c|c|c|}
\hline \multirow[b]{2}{*}{ Cortical layer } & \multicolumn{2}{|l|}{ PW group } & \multicolumn{2}{|l|}{ AW group } \\
\hline & Facilitating $^{a}$ & Depressing $^{b}$ & Facilitating & Depressing \\
\hline \multicolumn{5}{|l|}{ Touch condition } \\
\hline Layer $2 / 3$ & $9^{d}$ & $24^{c, d}$ & 4 & 13 \\
\hline Layer 4 barrels & 21 & 8 & 4 & 5 \\
\hline Layer 5a & 18 & 10 & 15 & 2 \\
\hline \multicolumn{5}{|l|}{ Whisking condition } \\
\hline Layer 2/3 & 6 & 28 & 6 & 10 \\
\hline Layer 4 barrels & 17 & 12 & 6 & 3 \\
\hline Layer 5a & $20^{d}$ & $7^{d}$ & $14^{d}$ & $2^{d}$ \\
\hline
\end{tabular}

${ }^{a}$ Mean normalized spike count (see Materials and Methods) in cycles $5-10$ was $>0$

${ }^{b}$ Mean normalized spike count was $<0$.

SSignificantly larger values (binomial distribution, $p<0.05$ ) are marked in bold.

${ }^{d}$ Units that could not be determined as either facilitating or depressing were not included here.

time-to-peak than layer $2 / 3$ in the Touch condition $(p<0.001$, layer $2 / 3$ vs $5 \mathrm{a}$; $p<0.06$, layer $2 / 3$ vs 4 -barrels; and $p<0.04$, layer 4-barrels vs $5 \mathrm{a}$ ) (Fig. 9D). Interestingly, the order of progression of the latency of the slow wave relative to train onset (Fig. 9) was opposite to that of the latency of the fast response components relative to whisk onset (Table 3 ): from layer $2 / 3$ to layers 4 and $5 a$ (Fig. 9D). For the slow wave, the time scales were an order of magnitude longer than the in-cycle latencies discussed in the previous section.

\section{Discussion}

In our artificial active whisking paradigm, dynamics of neuronal responses were affected by the presence of an object in a layerspecific manner. In layers $2 / 3$, the response was depressed in both
$\mathrm{L} 2 / 3$

L4 barrel

Whisking and Touch conditions, with more depression occurring in the Whisking condition. In layer $5 \mathrm{a}$, the response was facilitated in both Touch and Whisking conditions, whereas in layer 4-barrel, the response was facilitated only in the Touch condition. Facilitation was specific to the protraction phase; during retraction, responses always depressed, and the effect of object presence was complementary to its effect during protraction. Responses converged to a steady state within four to five cycles from train onset, after cessation of a slow wave response. During steady-state response, latency in the Touch condition was longer by 3-5 ms than in the Whisking condition. These results support the notion that cortical adaptation is not an automatic, activity-dependent mechanism but rather a process that depends on the sensory information conveyed by the activity and on the processing circuit. Ranging from depression to facilitation, adaptation is specific to the cortical layer and to the nature of the input, in accordance with previous results suggesting that different cortical layers in the barrel cortex are involved in different processing tasks, rather than all participating in a unified columnar task.

\section{Artificial versus natural whisking}

Although the principles of muscle-driven whisker movement and the basic patterns of movement trajectory are preserved in our experiments, the precise movements, mechanical interactions, and responses to touch may differ from those that occur during natural whisking (see discussion by Szwed et al., 2003). In awake rats, responses in the barrel cortex are modulated during active touch (Krupa et al., 2004; Ferezou et al., 2006). Active whisking increases background activity (Hentschke et al., 2005) and reduces response amplitude for passive but not active touch (Crochet and Petersen, 2006; Ferezou et al., 2006). In our paradigm, initiation of artificial whisking transiently increases background activity (e.g., slow wave in Figs. 3 and 9). In light of the results of Hentschke et al. (2005), the slow wave we observed, although triggered by the first input volley, might be initiated centrally, propagating back to and within S1. This is consistent with the superficial-to-deeper layer propagation we observed (Fig. 9) and with the fact that under the same conditions, no similar slow wave was observed in the thalamus (C. Yu, D. Derdikman, E. Ahissar, unpublished observation).

\section{Parallel pathways of active touch processing}

The laminar structure of the barrel cortex reflects the convergence of parallel afferent streams within each cortical column. The barrels in layer 4 and layer 5b/6a receive lemniscal afferents, layers 1 and $5 a$ receive paralemniscal afferents, and the septa in layer 4 receive both paralemniscal and extralemniscal (Diamond, 1995; Pierret et al., 2000; Bureau et al., 2006). With passive stimuli, we showed previously that these layers also display functional differences: the granular and infragranular input layers (layers 4, $5 \mathrm{a}$, and 5b) preserve the coding schemes of their thalamic counterparts, probably reflecting tight thalamocortical processing, 

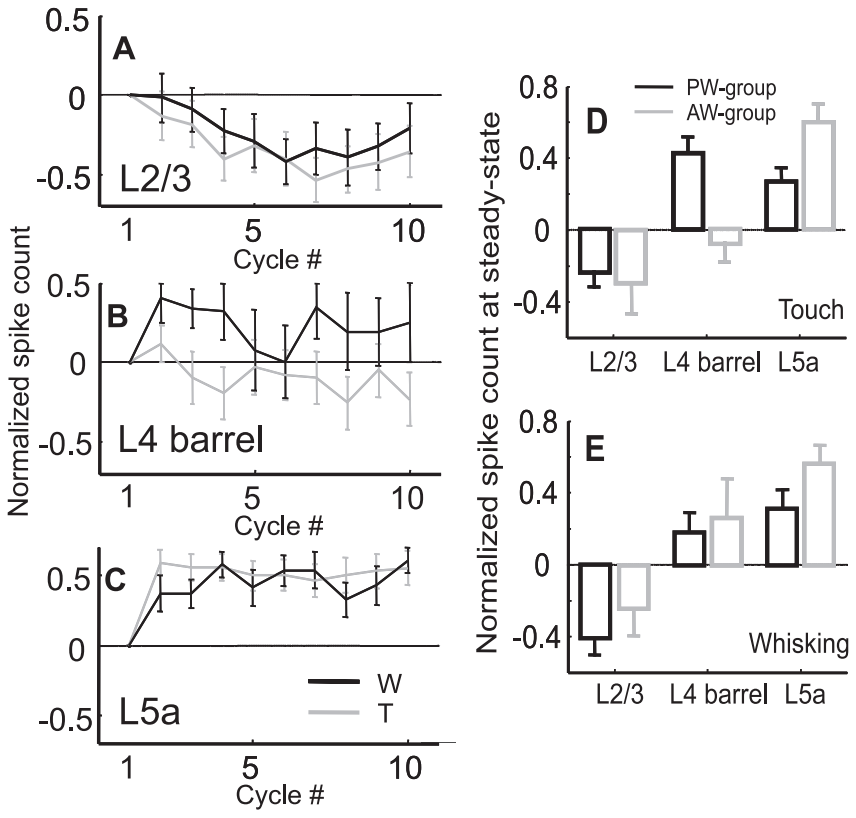

Figure 5. Dynamics of spike counts of AW neurons during protraction and comparison with responses to PW. A-C, Mean normalized protraction spike count of the AW group during artificial whisking in free air (black line) and against an object (gray line). $\boldsymbol{A}$, Layer $2 / 3$ ( $n=17)$. $\boldsymbol{B}$, Layer 4-barrels $(n=9)$. $\boldsymbol{C}$, Layer 5 a $(n=17)$. $\boldsymbol{D}, \boldsymbol{E}$, Comparison of the mean steady-state (cycles 5-10) normalized responses of the cortical layers for the PW (black) and AW (gray) groups for the Touch $(\boldsymbol{D})$ and Whisking $(\boldsymbol{E})$ conditions. Spike counts were measured during the first $60 \mathrm{~ms}$ from whisk onset and normalized according to the response in the first cycle. W, Whisking condition; T, touch condition.

and supragranular responses exhibit signs of integration of the parallel thalamocortical streams (Ahissar et al., 2000, 2001). Such integration is probably mediated via stream-specific pathways from layers 4 and 5a to layers 2 and 3 (Bernardo et al., 1990; Keller, 1995; Gottlieb and Keller, 1997; Kim and Ebner, 1999; Staiger et al., 2000; Shepherd and Svoboda, 2005; Bureau et al., 2006).

Studying the vibrissal system during active touch, using artificial whisking, we recently revealed a segregation of specific active touch signals among the afferent pathways. Primary afferents from the whisker follicle convey sensor motion (whisking), touch, and combinations of whisking and touch separately (Szwed et al., 2003). Active touch signals are conveyed in parallel up to the thalamus: whisking signals are conveyed by the paralemniscal, contact signals by the extralemniscal, and complex whisking-touch signals by the lemniscal pathway (Yu et al., 2006). Although all three pathways project to $S 1$, the first two also project from the thalamus to destinations other than S1, closing the sensory-motor loop at earlier levels (Cadusseau and Roger, 1990; Deschenes et al., 1998; Pierret et al., 2000).

Distributions of steady-state TI in layer 4 barrels and layer $5 \mathrm{a}$ show a significant amount of interlaminar overlap, larger than that observed in their thalamic counterparts (Yu et al., 2006). Nevertheless, the tendency of the thalamic segregation was preserved (Fig. 7): layer 5a neurons tended to respond similarly to whisking in air and whisking against object (TI, $\sim 0)$, similar to neurons in the paralemniscal thalamic nucleus POm (a rostral sector of the posterior complex of the thalamus), whereas layer 4 barrel neurons responded differentially, adding spikes on touch $(\mathrm{TI},>0)$, similar to neurons of the lemniscal thalamic nucleus VPMdm (dorsomedial sector of the ventroposteromedial nucleus). Layer 2/3 neurons showed an intermediate tendency. One

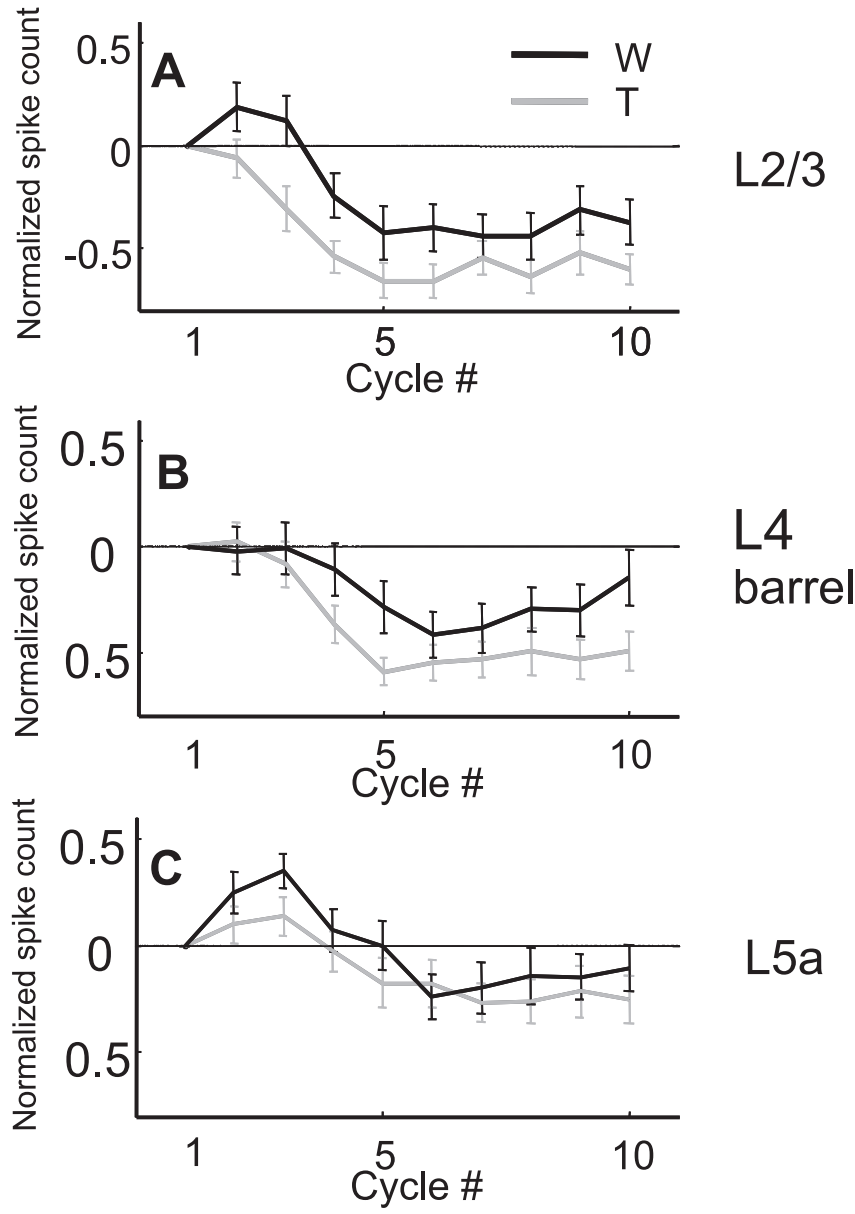

Figure 6. Dynamics of retraction spike counts of cortical layers. $\boldsymbol{A}$, Layer $2 / 3$ ( $n=34)$. $\boldsymbol{B}$, Layer 4 barrels $(n=29)$. C, Layer 5 a $(n=28)$. Spike count measured in the interval $100-160$ ms from whisk onset. Black, W, Whisking condition; gray, T, Touch condition.
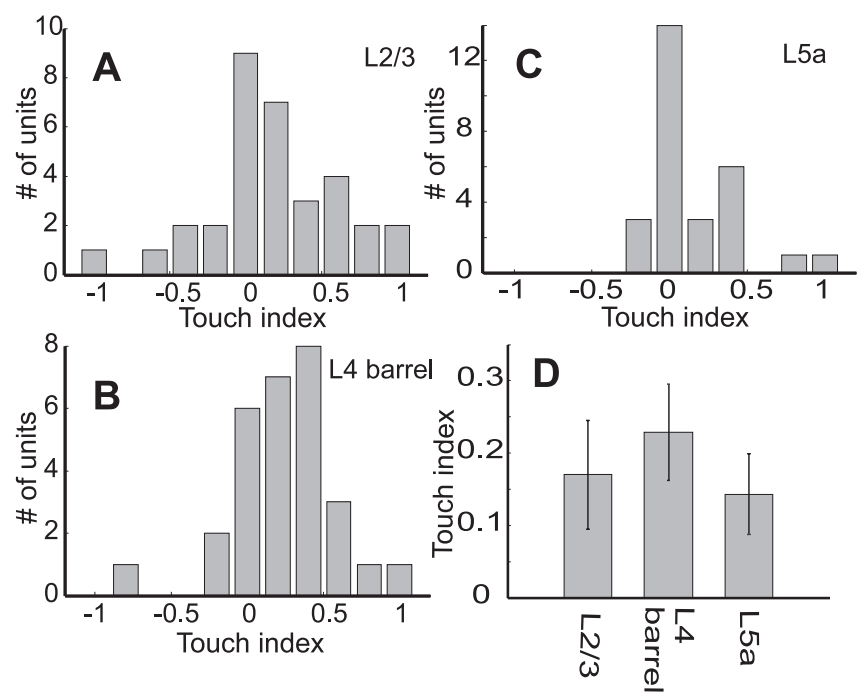

Figure 7. Comparison of mean steady-state responses during Touch and Whisking conditions. $\boldsymbol{A}-\boldsymbol{C}$, Distributions of Tl of single units at steady state (mean over cycles, $5-10$ ) in each layer ( $\boldsymbol{A}$, layer $2 / 3$; $\boldsymbol{B}$, layer 4 barrels; $\boldsymbol{C}$, layer 5a). $\boldsymbol{D}$, Mean steady-state $\mathrm{TI}( \pm S E M)$ in each layer.

interpretation of the laminar differences in connectivity, responses to passive touch, responses to active touch, and nature of adaptation demonstrated here is that the paralemniscal system is involved in processing of whisking kinematics and its coordina- 

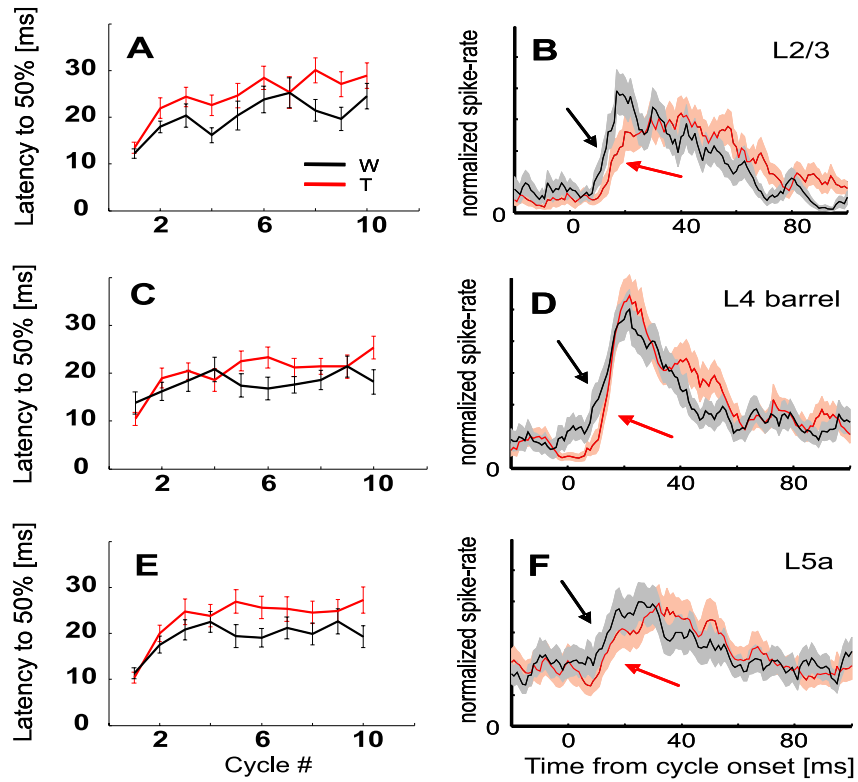

Figure 8. Dynamics of response latency. $A-E$, Mean latency from whisk onset to $50 \%$ of maximal response in each cycle for Touch (red) and Whisking (black) conditions. $\boldsymbol{A}, \boldsymbol{B}$, Layer $2 / 3$ ( $n=34$ units). $\boldsymbol{C}, \boldsymbol{D}$, Layer 4 barrels $(n=29) . \boldsymbol{E}, \boldsymbol{F}$, Layer 5 a $(n=28) . \boldsymbol{B}, \boldsymbol{D}, \boldsymbol{F}$, Mean steady-state normalized PSTHs, which demonstrate the earlier onset for the Whisking condition (black arrows) than the Touch condition (red arrows). Shaded areas around each PSTH denote SEMs. W, Whisking condition; T, Touch condition.

Table 3. Mean latencies (ms) to half-peak from whisk onset for Touch and Whisking conditions

\begin{tabular}{llllll}
\hline & \multicolumn{2}{l}{ First cycle latencies } & & \multicolumn{2}{l}{ Steady-state latencies } \\
\cline { 2 - 3 } Cortical layer & Whisking $^{a}$ & Touch $^{a}$ & & Whisking & Touch \\
\hline Layer 2/3 & $12.4 \pm 1.0^{\mathrm{b}}$ & $13.7 \pm 1.2$ & & $24.7 \pm 1.9$ & $29.4 \pm 2.1$ \\
Layer 4 barrels & $13.8 \pm 2.3$ & $10.5 \pm 1.4$ & & $19.0 \pm 1.4$ & $22.6 \pm 1.7$ \\
Layer 5a & $11.3 \pm 1.2$ & $10.4 \pm 1.2$ & & $21.0 \pm 1.4$ & $26.3 \pm 2.0$ \\
\hline
\end{tabular}

${ }^{a}$ Condition.

${ }^{b}$ Mean \pm SEM.

tion with the motor system, whereas the lemniscal system processes information related to object identity (Yu et al., 2006). Because whisking kinematics is similar for neighboring whiskers (Sellien et al., 2005), integration within layer 5a across neighboring columns (Schubert et al., 2006) makes sense. In contrast, columnar segregation within layer 4 (Staiger et al., 2004) is consistent with spatial processing of single-whisker resolution that is required for object identification. The reduced segregation of whisking and touch signals in the input layers of the cortex, compared with the thalamus (Yu et al., 2006), probably reflects the beginning of interaction between the two processing streams, an interaction which becomes stronger in layer $2 / 3$ and which is required for object identification. The strong segregation at the thalamus suggests that uncontaminated whisking signals are required for appropriate whisking control, most likely mediated by subcortical sensory-motor loops. A third major aspect of active touch, object localization, is suggested to be implemented by an integration of the paralemniscal (whisking) and extralemniscal (contact) signals (Yu et al., 2006). Such integration might take place in layer 4 septa of S1, or more likely in S2, which is a major target of both pathways (Spreafico et al., 1987; Pierret et al., 2000; Alloway et al., 2003; Kwegyir-Afful and Keller, 2004).
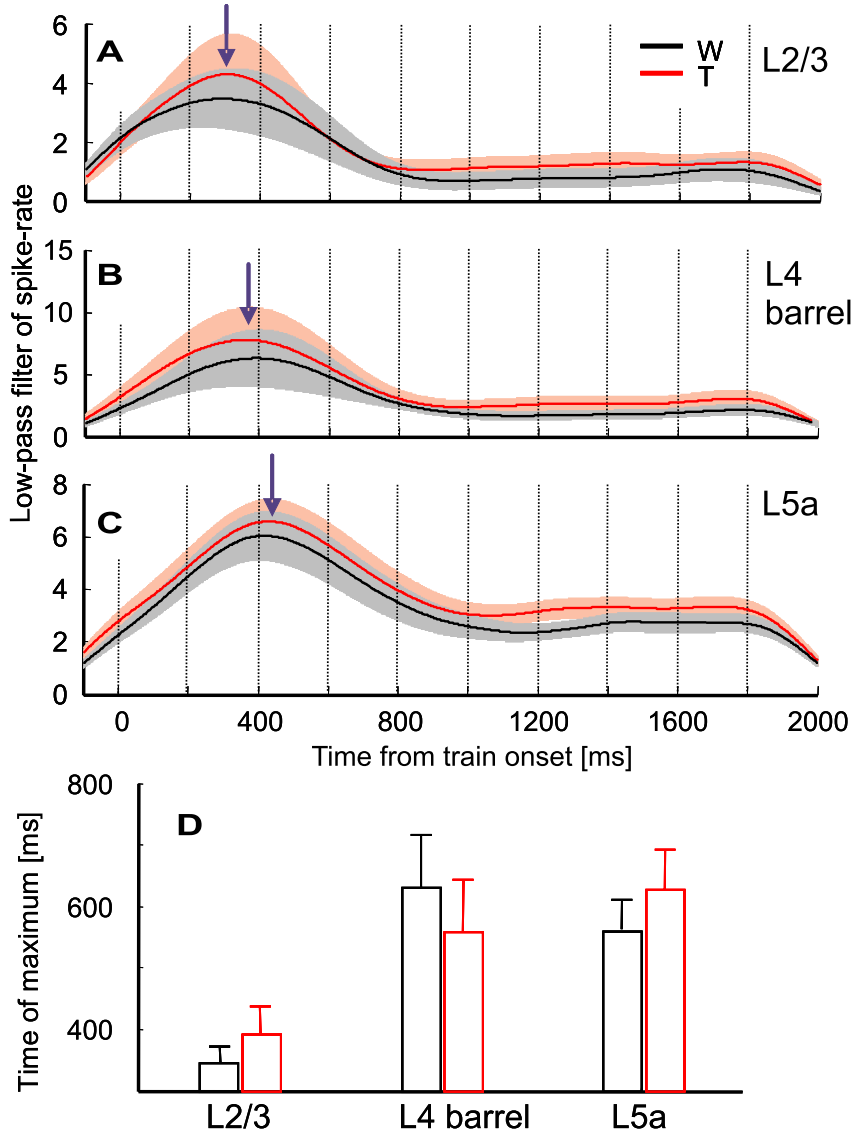

Figure 9. Dynamics of slow-wave responses. $A-C$, Low-pass $(2 \mathrm{~Hz})$ version of the mean population PSTHs for both Touch (red) and Whisking (black) conditions (derived from Fig. 3 PSTHs). A, Layer $2 / 3$ ( $n=34$ units). B, Layer 4 barrels $(n=29)$. C, Layer 5 a $(n=28)$. Shaded areas around each PSTH denote SEMs. Arrows indicate the peak of the slow wave during the Touch condition. $\boldsymbol{D}$, Mean latency from whisk-train onset to the peak of the slow wave for both Touch (red) and Whisking (black) conditions. W, Whisking condition; T, Touch condition.

\section{Response facilitation versus depression}

In our study, most layer 4 barrel units facilitated during the whisking train in the Touch condition, and most layer 5a units facilitated in both Touch and Whisking conditions, whereas layer $2 / 3$ cells exhibited response depression (Fig. 4 , Table 2 ). In most studies reporting on adaptation during stimulus trains, stimuli were applied to passive (i.e., motionless) whiskers, and responses were depressed from first cycle to steady state (Simons, 1978; Brumberg et al., 1999; Ahissar et al., 2000, 2001; Ego-Stengel et al., 2001, 2005; Chung et al., 2002; Castro-Alamancos, 2004; Khatri et al., 2004; Webber and Stanley, 2004; Higley and Contreras, 2006). In only a few studies, response components of some barrel cortex neurons were facilitated in response to passive touch (Brecht and Sakmann, 2002; Garabedian et al., 2003). As demonstrated here, with active touch, the response of the entire population is facilitated in layers 4 and 5a. Response facilitation was evident with spike count but not necessarily with amplitude. In fact, layer $5 \mathrm{a}$ amplitudes during steady state were usually lower than those during the first cycle (Fig. 3). The significance of either amplitude or spike count changes cannot be appreciated before their readout mechanisms are clarified.

In contrast to their response during protraction, cortical neurons did not exhibit facilitation during retraction. The difference between the dynamics during protraction and retraction might be related to directional selectivity (Andermann and Moore, 
2006) and/or to the order of activation (Webber and Stanley, 2006), because in our experiments, protraction always preceded retraction. The functional role of this differential adaptation in the processing of active touch is yet to be determined.

\section{Touch-specific adaptation}

Active exploration involves head movements; thus, even if a whisker repeats its scanning pattern from cycle to cycle, it may not sample the same location in different cycles (Knutsen et al., 2005, 2006). Therefore, even if input signals are identical from cycle to cycle, they convey new information in world coordinates (Ahissar and Zacksenhouse, 2001). Because of this, a mechanism that prevents or avoids depression to identical inputs during active sensing is required.

Adaptation mechanisms can be divided into output- and input-specific classes (Gollisch and Herz, 2004; Ulanovsky et al., 2004). We believe that the stimulus-specific nature of our results suggests that the second type of mechanism is valid here. Importantly, however, stimulus specificity in the active whisking case does not depend on a difference in repetition frequency, as is commonly the case with passive stimuli (Grill-Spector et al., 1999; Eytan et al., 2003; Ulanovsky et al., 2004).

Several functional roles have been suggested for adaptation, among them gain control (Salinas and Abbott, 1997), improvement in stimulus discriminability (Ringo, 1996), optimization of information transmission (Barlow and Foldiak, 1989; Muller et al., 1999; Brenner et al., 2000), optimization of energy (Barlow, 1972; Laughlin et al., 1998; Turrigiano and Nelson, 2004), and novelty detection (Eytan et al., 2003; Ranganath and Rainer, 2003; Ulanovsky et al., 2003). Most of these functions entail depression of responses to the more frequent stimuli. The results presented here demonstrate that responses to frequent stimuli can depress, remain unchanged, or facilitate, depending on the information conveyed by the stimulus and the processing layer. This suggests that adaptation might reflect the dynamics of a given circuit toward a generation of a neuronal representation, which is specific to both the stimulus and the processing circuit.

\section{References}

Ahissar E, Arieli A (2001) Figuring space by time. Neuron 32:185-201.

Ahissar E, Zacksenhouse M (2001) Temporal and spatial coding in the rat vibrissal system. Prog Brain Res 130:75-87.

Ahissar E, Sosnik R, Haidarliu S (2000) Transformation from temporal to rate coding in a somatosensory thalamocortical pathway [see comments]. Nature 406:302-306.

Ahissar E, Sosnik R, Bagdasarian K, Haidarliu S (2001) Temporal frequency of whisker movement. II. Laminar organization of cortical representations. J Neurophysiol 86:354-367.

Alloway KD, Hoffer ZS, Hoover JE (2003) Quantitative comparisons of corticothalamic topography within the ventrobasal complex and the posterior nucleus of the rodent thalamus. Brain Res 968:54-68.

Andermann ML, Moore CI (2006) A somatotopic map of vibrissa motion direction within a barrel column. Nat Neurosci 9:543-551.

Armstrong-James M, Fox K, Das-Gupta A (1992) Flow of excitation within rat barrel cortex on striking a single vibrissa. J Neurophysiol 68:13451358.

Barlow HB (1972) Single units and sensation: a neuron doctrine for perceptual psychology. Perception 1:371-394.

Barlow HB, Foldiak P (1989) Adaptation and decorrelation in the cortex. In: The computing neuron (Durbin R, Miall C, Mitchison G, eds), pp 54-72. Reading, MA: Addison-Wesley.

Berg RW, Kleinfeld D (2003) Rhythmic whisking by rat: retraction as well as protraction of the vibrissae is under active muscular control. J Neurophysiol 89:104-117.

Bernardo KL, McCasland JS, Woolsey TA, Strominger RN (1990) Local intra- and interlaminar connections in mouse barrel cortex. J Comp Neurol 291:231-255.
Brecht M, Sakmann B (2002) Dynamic representation of whisker deflection by synaptic potentials in spiny stellate and pyramidal cells in the barrels and septa of layer 4 rat somatosensory cortex. J Physiol (Lond) 543:49-70.

Brecht M, Preilowski B, Merzenich MM (1997) Functional architecture of the mystacial vibrissae. Behav Brain Res 84:81-97.

Brenner N, Bialek W, van Steveninck RD (2000) Adaptive rescaling maximizes information transmission. Neuron 26:695-702.

Brown AW, Waite PM (1974) Responses in the rat thalamus to whisker movements produced by motor nerve stimulation. J Physiol (Lond) 238:387-401.

Brumberg JC, Pinto DJ, Simons DJ (1999) Cortical columnar processing in the rat whisker-to-barrel system. J Neurophysiol 82:1808-1817.

Bureau I, von Saint Paul F, Svoboda K (2006) Interdigitated paralemniscal and leminiscal pathways in the mouse barrel cortex. PLoS Biol, in press.

Cadusseau J, Roger M (1990) Distribution of the efferent projections of the rat posterior thalamic nucleus as revealed by Phaseolus vulgaris immunohistochemistry. J Hirnforsch 31:459-465.

Carvell GE, Simons DJ (1990) Biometric analyses of vibrissal tactile discrimination in the rat. J Neurosci 10:2638-2648.

Castro-Alamancos MA (2004) Absence of rapid sensory adaptation in neocortex during information processing states. Neuron 41:455-464.

Celikel T, Szostak VA, Feldman DE (2004) Modulation of spike timing by sensory deprivation during induction of cortical map plasticity. Nat Neurosci 7:534-541.

Chung S, Li X, Nelson SB (2002) Short-term depression at thalamocortical synapses contributes to rapid adaptation of cortical sensory responses in vivo. Neuron 34:437-446.

Crochet S, Petersen CC (2006) Correlating whisker behavior with membrane potential in barrel cortex of awake mice. Nat Neurosci 9:608-610.

Derdikman D, Knutsen PM, Ahissar E (2003) Integrating kinematic data and extracellular recordings in the "electrically whisking" rat: effects of whisker angle and curvature. Paper presented at Barrels XVI meeting. New Orleans, Louisiana, November.

Deschenes M, Veinante P, Zhang ZW (1998) The organization of corticothalamic projections: reciprocity versus parity. Brain Res Brain Res Rev 28:286-308.

Diamond ME (1995) Somatosensory thalamus of the rat. In: Cerebral cortex, Vol 11 (Jones EG, Diamond IT, eds), pp 189-219. New York: Plenum.

Ego-Stengel V, Shulz DE, Haidarliu S, Sosnik R, Ahissar E (2001) Acetylcholine-dependent induction and expression of functional plasticity in the barrel cortex of the adult rat. J Neurophysiol 86:422-437.

Ego-Stengel V, Mello e Souza T, Jacob V, Shulz DE (2005) Spatiotemporal characteristics of neuronal sensory integration in the barrel cortex of the rat. J Neurophysiol 93:1450-1467.

Eytan D, Brenner N, Marom S (2003) Selective adaptation in networks of cortical neurons. J Neurosci 23:9349-9356.

Fanselow EE, Nicolelis MAL (1999) Behavioral modulation of tactile responses in the rat somatosensory system. J Neurosci 19:7603-7616.

Ferezou I, Bolea S, Petersen CC (2006) Visualizing the cortical representation of whisker touch: voltage-sensitive dye imaging in freely moving mice. Neuron 50:617-629.

Garabedian CE, Jones SR, Merzenich MM, Dale A, Moore CI (2003) Bandpass response properties of rat SI neurons. J Neurophysiol 90:1379-1391.

Gollisch T, Herz AVM (2004) Input-driven components of spike-frequency adaptation can be unmasked in vivo. J Neurosci 24:7435-7444.

Gottlieb JP, Keller A (1997) Intrinsic circuitry and physiological properties of pyramidal neurons in rat barrel cortex. Exp Brain Res 115:47-60.

Grill-Spector K, Kushnir T, Edelman S, Avidan G, Itzchak Y, Malach R (1999) Differential processing of objects under various viewing conditions in the human lateral occipital complex. Neuron 24:187-203.

Gustafson JW, Felbain-Keramidas SL (1977) Behavioral and neural approaches to the function of the mystacial vibrissae. Psychol Bull $84: 477-488$.

Hellweg FC, Schultz W, Creutzfeldt OD (1977) Extracellular and intracellular recordings from cat's cortical whisker projection area: thalamocortical response transformation. J Neurophysiol 40:463-479.

Hentschke H, Haiss F, Schwarz C (2005) Central signals rapidly switch tactile processing in rat barrel cortex during whisker movements. Cereb Cortex 16:1142-1156.

Higley MJ, Contreras D (2006) Balanced excitation and inhibition determine spike timing during frequency adaptation. J Neurosci 26:448-457. 
Keller A (1995) Synaptic organization of the barrel cortex. In: Cerebral cortex, Vol 11 (Jones EG, Diamond IT, eds), pp 221-262. New York: Plenum.

Kelly MK, Carvell GE, Kodger JM, Simons DJ (1999) Sensory loss by selected whisker removal produces immediate disinhibition in the somatosensory cortex of behaving rats. J Neurosci 19:9117-9125.

Khatri V, Hartings JA, Simons DJ (2004) Adaptation in thalamic barreloid and cortical barrel neurons to periodic whisker deflections varying in frequency and velocity. J Neurophysiol 92:3244-3254.

Kim U, Ebner FF (1999) Barrels and septa: separate circuits in rat barrels field cortex. J Comp Neurol 408:489-505.

Kleinfeld D, Berg RW, O'Connor SM (1999) Anatomical loops and their electrical dynamics in relation to whisking by rat. Somatosens Motor Res $16: 69-88$.

Kleinfeld D, Ahissar E, Diamond ME (2006) Active sensation: insights from the rodent vibrissa sensorimotor system. Curr Opin Neurobiol 16:435-444.

Knutsen PM, Derdikman D, Ahissar E (2005) Tracking whisker and head movements in unrestrained behaving rodents. J Neurophysiol 93:2294-2301.

Knutsen P, Pietr M, Ahissar E (2006) Haptic object localization in the vibrissal system: behavior and performance. J Neurosci 26:8451-8464.

Krupa DJ, Wiest MC, Shuler MG, Laubach M, Nicolelis MA (2004) Layerspecific somatosensory cortical activation during active tactile discrimination. Science 304:1989-1992.

Kwegyir-Afful EE, Keller A (2004) Response properties of whisker-related neurons in rat second somatosensory cortex. J Neurophysiol 92:2083-2092.

Laughlin SB, de Ruyter van Steveninck RR, Anderson JC (1998) The metabolic cost of neural information. Nat Neurosci 1:36-41.

Manns ID, Sakmann B, Brecht M (2004) Sub- and suprathreshold receptive field properties of pyramidal neurons in layers $5 \mathrm{~A}$ and $5 \mathrm{~B}$ of rat somatosensory barrel cortex. J Physiol 556:601-622.

Mountcastle VB, Davies PW, Berman AL (1957) Response properties of neurons of cat's somatic sensory cortex to peripheral stimuli. J Neurophysiol 20:374-407.

Muller JR, Metha AB, Krauskopf J, Lennie P (1999) Rapid adaptation in visual cortex to the structure of images. Science 285:1405-1408.

Pierret T, Lavallee P, Deschenes M (2000) Parallel streams for the relay of vibrissal information through thalamic barreloids. J Neurosci 20:7455-7462.

Ranganath C, Rainer G (2003) Neural mechanisms for detecting and remembering novel events. Nat Rev Neurosci 4:193-202.

Ringo JL (1996) Stimulus specific adaptation in inferior temporal and medial temporal cortex of the monkey. Behav Brain Res 76:191-197.

Salinas E, Abbott LF (1997) Invariant visual responses from attentional gain fields. J Neurophysiol 77:3267-3272.

Schubert D, Kotter R, Luhmann HJ, Staiger JF (2006) Morphology, electrophysiology and functional input connectivity of pyramidal neurons characterizes a genuine layer va in the primary somatosensory cortex. Cereb Cortex 16:223-236.
Sellien H, Eshenroder DS, Ebner FF (2005) Comparison of bilateral whisker movement in freely exploring and head-fixed adult rats. Somatosens Mot Res 22:97-114.

Shepherd GMG, Svoboda K (2005) Laminar and columnar organization of ascending excitatory projections to layer $2 / 3$ pyramidal neurons in rat barrel cortex. J Neurosci 25:5670-5679.

Simons DJ (1978) Response properties of vibrissa units in rat SI somatosensory neocortex. J Neurophysiol 41:798 -820.

Sosnik R, Haidarliu S, Ahissar E (2001) Temporal frequency of whisker movement. I. Representations in brain stem and thalamus. J Neurophysiol 86:339-353.

Spreafico R, Barbaresi P, Weinberg RJ, Rustioni A (1987) SII-projecting neurons in the rat thalamus: a single- and double-retrograde-tracing study. Somatosens Res 4:359-375.

Staiger JF, Kotter R, Zilles K, Luhmann HJ (2000) Laminar characteristics of functional connectivity in rat barrel cortex revealed by stimulation with caged-glutamate. Neurosci Res 37:49-58.

Staiger JF, Flagmeyer I, Schubert D, Zilles K, Kotter R, Luhmann HJ (2004) Functional diversity of layer IV spiny neurons in rat somatosensory cortex: quantitative morphology of electrophysiologically characterized and biocytin labeled cells. Cereb Cortex 14:690-701

Szwed M, Bagdasarian K, Ahissar E (2003) Encoding of vibrissal active touch. Neuron 40:621-630.

Turrigiano GG, Nelson SB (2004) Homeostatic plasticity in the developing nervous system. Nat Rev Neurosci 5:97-107.

Ulanovsky N, Las L, Nelken I (2003) Processing of low-probability sounds by cortical neurons. Nat Neurosci 6:391-398.

Ulanovsky N, Las L, Farkas D, Nelken I (2004) Multiple time scales of adaptation in auditory cortex neurons. J Neurosci 24:10440-10453.

Vincent SB (1912) The function of the vibrissae in the behavior of the white rat. Behav Monographs 1:7-81.

Webber RM, Stanley GB (2004) Nonlinear encoding of tactile patterns in the barrel cortex. J Neurophysiol 91:2010-2022.

Webber RM, Stanley GB (2006) Transient and steady-state dynamics of cortical adaptation. J Neurophysiol 95:2923-2932.

Welker E, Armstrong-James M, Van der Loos H, Kraftsik R (1993) The mode of activation of a barrel column-response properties of single units in the somatosensory cortex of the mouse upon whisker deflection. Eur J Neurosci 5:691-712.

Welker WI (1964) Analysis of sniffing of the albino rat. Behaviour 12:223-244.

Woolsey TA, Van der Loos H (1970) The structural organization of layer IV in the somatosensory region (SI) of mouse cerebral cortex. The description of a cortical field composed of discrete cytoarchitectonic units. Brain Res 17:205-242.

Yu C, Derdikman D, Haidarliu S, Ahissar E (2006) Parallel thalamic pathways for whisking and touch signals in the rat. PLoS Biol 4:e124.

Zucker E, Welker WI (1969) Coding of somatic sensory input by vibrissae neurons in the rat's trigeminal ganglion. Brain Res 12:138-156. 